\title{
Diversity and Distribution of Ichthyofauna and Decapods within Colombo Port, Sri Lanka
}

\author{
Marasinghe MMKI \& Ranatunga RRMKP \\ Department of Zoology, Faculty of Applied Sciences, University of Sri Jayewardenepura, Sri Lanka.
}

\begin{abstract}
The taxonomic composition of ichthyofauna and decapods inhabited in Colombo port were studied. Sampling was carried out for nine months from April to December 2013 using multiple sampling techniques such as crab traps, hook and lines, gee-minnow traps, fish cage traps, cast nets, scoop nets as well as visual observations. Out of the 45 species of ichthyofauna, 44 species were belonging to Class Actinopterygii, and only one species belonged to Class Chondrichthyes. 5 species of crabs of the families Xanthidae, Portunidae, Grapsidae, and Menippidae were also recorded. The highest number of species were recorded from the site South Jetty followed by Passenger Jetty, Tug and Launch and South Asia Gateway Terminal. According to the findings, 30 species of fishes and 4 species of crabs were new records for the Colombo port environment. Two near threaten fishes, Epinephelus malabaricus and Epinephelus coioides were also recorded.
\end{abstract}

KEYWORDS: Taxonomic composition, Colombo port, Near Threaten, Fish, Crabs

Corresponding author: R R M K P Ranatunga, Email: ranatunga@sci.sjp.ac.lk 


\section{INTRODUCTION}

Native biodiversity is very precious since it represents the indigenous wealth of a country. As a result of anthropogenic activities and human-induced natural phenomenon, both faunal and floral biodiversity of aquatic ecosystems are bounded to demolish. From all, marine ecosystems considered to be the least concerned with regard to conservation, resulting in various implications in ecological conditions of the faunal community. Marine bio-invasions caused by the long history of transportation considered to be one of the colossal issues, which negatively affect the native ecology, economy, and human health. It is recognized that the magnitude of the impacts results from introduction on native species has become significant (Currie et al., 1998). Many individuals and organizations have engaged in addressing this issue in various aspects; many port surveys and ballast water management programs have been carried out worldwide in the investigation of introduced species (Neil and Stafford, 2004; Bennet et al., 2006; Inglis et al., 2006; Inglis et al., 2008). The issue is not addressed properly in Sri Lanka, and information on native marine biodiversity is lacking, which is a fundamental requirement in conserving biodiversity against marine bioinvasions. Therefore, present study targeted taxonomic composition and distribution of ichthyofauna and decapod assemblages in order to fill the existing data gaps on faunal diversity within Colombo port. Ports are one of the major sources of marine biological invasions and records of marine biodiversity is imperative in order to detect and monitor any possible bioinvasion.

\section{MATERIALS \& METHODS}

Field sampling was carried out for two to three days per month between April and December 2013. Sampling was done at ten sampling locations (Figure 1), and organisms were collected using multiple sampling techniques. The selection of sampling locations and methods closely followed the guideline provided by Centre for Research on Invasive Marine Pests (CRIMP) protocol developed for introducing marine pest species surveys in Australian ports (Hewitt and Martin, 2001), although some modifications were implemented to this protocol, i.e. use of, traditional crab trapping method, hook and lines, gee-minnow traps for prawns and larval stages of fishes and use of different designs of fish net trap to suit local situations.

This study was conducted after obtaining ethical approval from the ethical review committee of University of Sri Jayewardenepura, Sri Lanka and Lady Ridgeway Hospital for Children, Sri Lanka.

Fishes were collected using mainly baited hooks and line, fish traps, cast net, geeminnow traps (Figure 2). Crabs were collected using baited crab traps, crab rings, hand nets and laboratory tongs (Figure 3) and crab rings were used mainly for the collection of bottom inhabiting crabs. Visual observations were also made in order to augment any species that would miss out of sampling due to inefficiency of the collecting methods. 


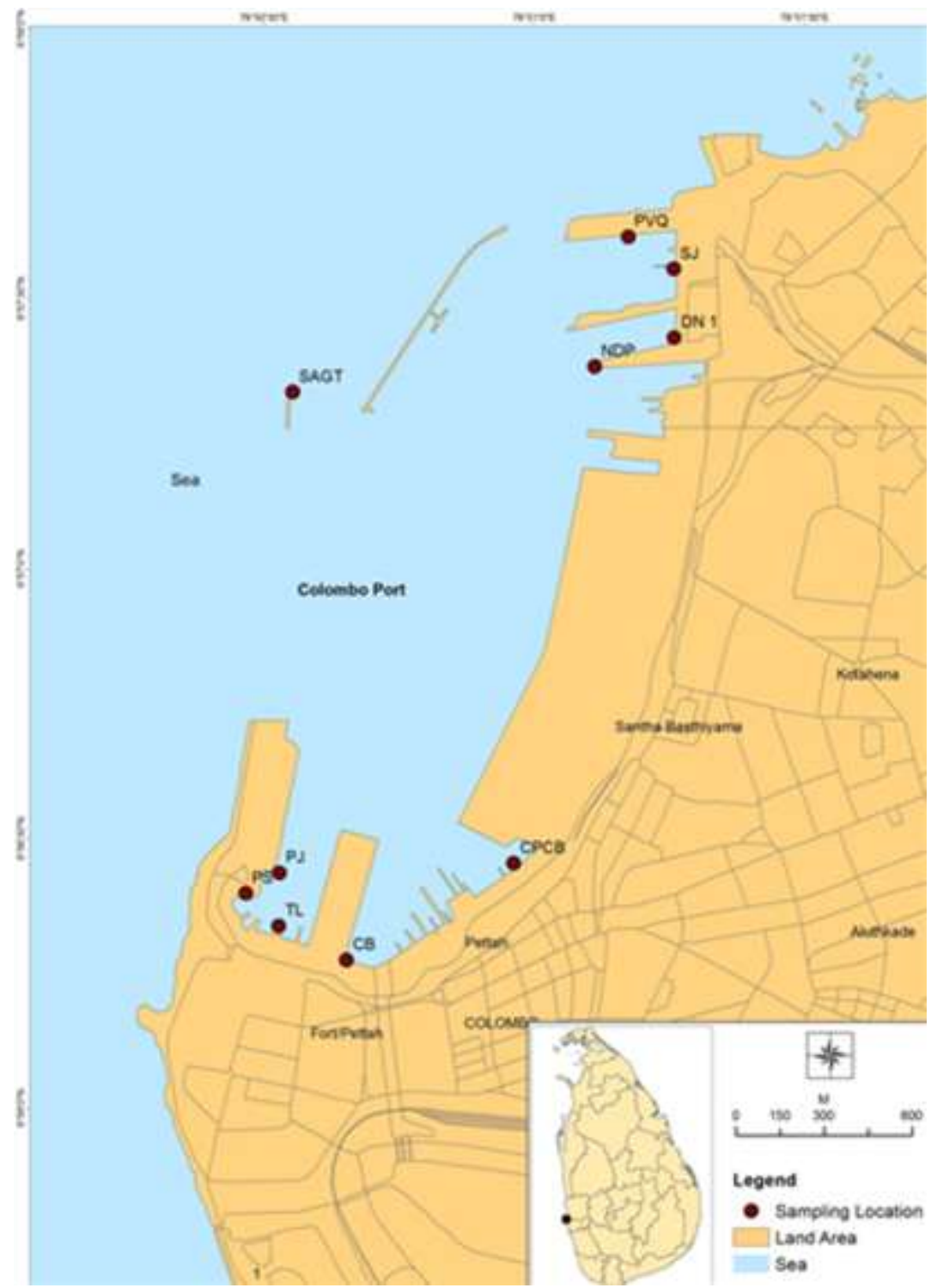

Figure 1: Sampling points (marked in red circles) within the Colombo port (SAGT: South Asia Gateway Terminal, PJ: Passenger Jetty, PS: Police Station, TL: Tug and Launch, CB: Canal Berth,CPCB: China Pier Cross : New Dock Pier, DN1: Dock No 1, SJ: South Jetty and PVQ: Prince Vijaya Quay).

Sampled fishes and crabs were photographed, and species which were not identified on site were preserved in $10 \%$ formalin and brought to the laboratory for further identification. Specimens were identified using fish identification guides and available databases (Allen, 2002; Tavares, 2002; Eschmeyer, 2013;
Froese and Pauly, 2013; Marine Species Identification Portal, 2013; Palomares and Pauly, 2013; Invasive Species Specialist Group, 2015;; WoRMS, 2013). 

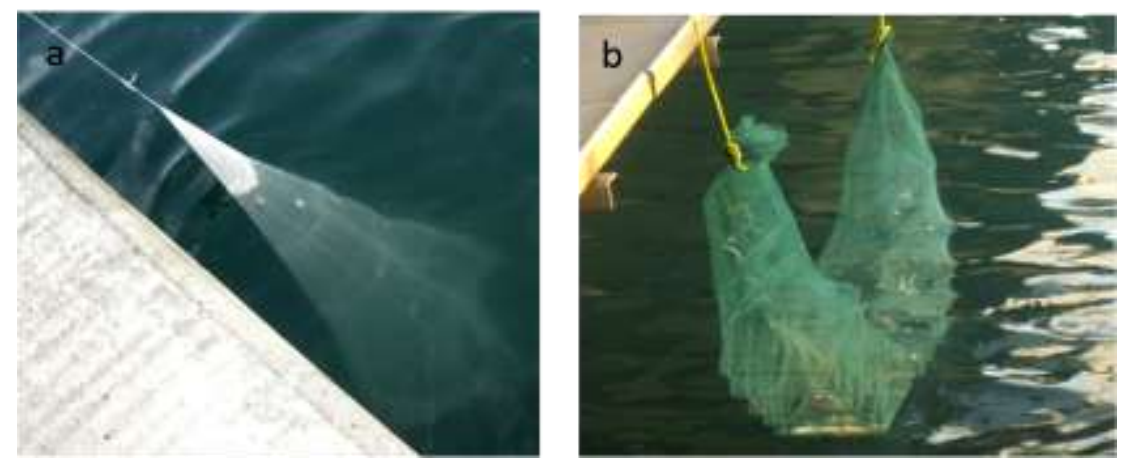

Figure 2: Fish sampling methods, a: cast net; b: baited fish net trap
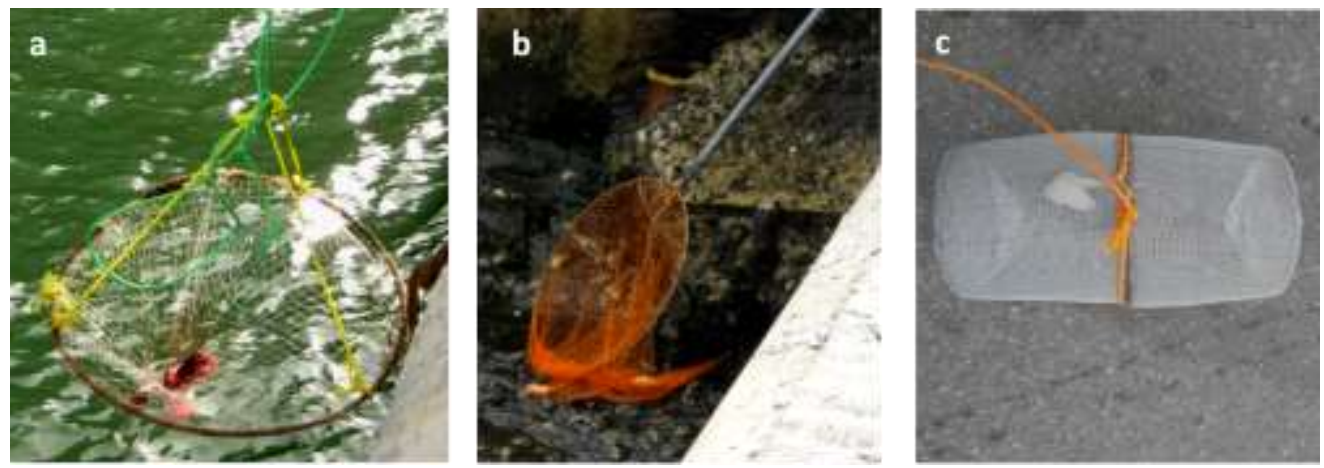

Figure 3: Crab sampling methods; a: Baited traditional crab ring; b: Scoop net; c: Baited Gee-minnow trap

\section{RESULTS AND DISCUSSION}

Out of all the species recorded, 45 species were fishes, and 5 species were crabs. To date, there have been only two detailed studies carried out in close proximity to Colombo port and adjacent coastal areas for the investigation of mobile macro faunal assemblages. Study conducted by NARA (1996) in the North side of the Colombo port recorded 12 fish species which were common to present study. Whereas, 33 species of fishes found in the present study have not recorded in the NARA (1996) study. Moreover, another study by University of Moratuwa (2011) conducted close to the South side of the port recorded eight fish species common to both studies. In total, 15 fish species found in the present study were common to previous studies embracing 30 newly recorded fish species for Colombo port environment.

The species distribution within the port environment was significantly different, and the majority of fishes observed in this study were reef-associated. Highest numbers of fish species were recorded from SJ (27) followed by 20 species in PJ, 18 species in TL, and 16 species in SAGT (Table 1). Lowest number of fishes were recorded from $\mathrm{CB}, \mathrm{CPCB}, \mathrm{DN} 1$, and NDP. However, compared to previous studies number of coral-associated fish species was low in the present study which is apparent as per the explanations given by Rajasuriya (2002), change in water quality, urban pollution, 
increased freshwater flow due to upstream irrigation schemes and other invasive organisms in the port environment can be the major causes for decrease in reef-associated fishes in the port environment. Moreover, due to enormous development practices in the port premises such as the construction of the south harbor and development of the north harbor may cause sitespecific damages in developing fish community associated with reef areas located in PJ and SJ (Joseph, 2003).

Presence of Mugil cephalus in all sampling locations excluding ND1 and NDP with a considerable population size was significant due to their high tolerance to harsh environmental conditions (Rajkumar and Milton, 2011; Waltham et al., 2013) and also, their egg development and hatching occurs in various ranges of salinities, between 10 and 55 ppt (Lee and Menu, 1981) resulting in a higher reproductive potential.

Two Near Threaten (NT) species were recorded from the present study, i.e. Epinephelus malabaricus, and Epinephelus coioides, where E. malabaricus was also recorded in the NARA (1996) study and these species were restricted to TL and PVQ sampling locations (Table 1). Further attention should be taken in conserving these species as they are threatened by fishing, habitat loss and disturbances through port activities. Out of the 45 species of fishes, none of the fishes were recorded as introduced or invasive. However, Pterois volitans (IndoPacific red lionfish) recoded in the port can be highly invasive and listed in the global invasive database (ISSG, 2013). Since they are native to Indian ocean, not considered as invasive in our waters. According to the literature, this is observable as there were only a minute amount of fishes recorded in port surveys as introduced.
Present study recorded 5 species of crabs belonging to families of Grapsidae, Menippidae, Xanthidae, and Portunidae (Table 2). The abundance of crabs were high in SAGT and SJ. However, in terms of diversity, SJ and PVQ recorded the highest number of crab species. In PVQ, crab species inhabited in water columns and bottom were common (Charybdis hellerii, Atergatis floridus and Menippe rumphii). Furthermore, it was noted that Graspidae crabs were abundant in SAGT and PJ.

According to Jayamanne (2011), there are 54 species of crabs found in brackish and marine water habitats of the country belonging to families of Calappidae, Leucosidae, Portunidae, and Grapsidae. However, the present study comprises of crabs belonging to four families Grapsidae, Menippidae, Xanthidae, and Portunidae (Table 2). Consequently, adding two new families to the Jayamanna (2011), i.e. Menippidae and Xanthidae.

According to the present study, graspidae crabs were the most abundant crab species in the port premises may be due to their high tolerance to a range of salinities from fresh to hypersaline, semi-terrestrial and air-breathing habits making them tolerant of low oxygen levels and salinity differences in sampling locations (Frusher et al., 1994; Lee, 1998). Furthermore, they have a wide range of feeding habits from detritivory, to herbivory and to carnivory (Kent and McGuinness, 2010). All these factors may have corresponded to their wider range distribution across varying habitats. 


\section{Family/Species}

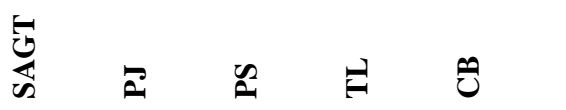

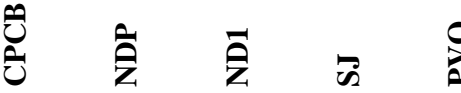

Acanthurus grammoptilus*

Acanthurus mata

Ctenochaetus striatus*

Ambassis vachellii

Caesio caerulaurea*

Caesio xanthonota

Caranx tille*

Chaetodon auriga*

Chaetodon collare*

Heniochus diphreutes

Dasyatidae

Remora australis

Platax orbicularis

Bathygobius cocosensis?

Istigobius decoratus*

Holocentridae

Photopectoralis bindus

Lethrinus lentjan

Lethrinus nebulosus

Lutjanus fulvus

Lutjanus russellii

Monodactylus argenteus

Liza vaigiensis

Mugil cephalus

Uropterygius concolor

Scolopsis vosmeri

Pomacanthus semicirculatus

Abudefduf vaigiensis

Abudefduf septemfasciatus

Neopomacentrus violescens*

Neopomacentrus cyanomos

Scarus ghobban

Scatophagus argus

Scorpaenopsis venosa

Pterois volitans

Cephalopholis formosa

Epinephelus coioides**

Epinephelus malabaricus**

Epinephelus sp.

Siganus javus

Siganus lineatus

Sillago sihama

Terapon jarbua

Arothron immaculatus

Marilyna darwinii

$+$

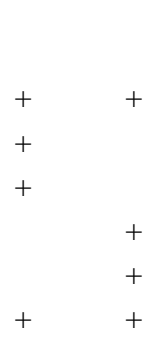

$+$

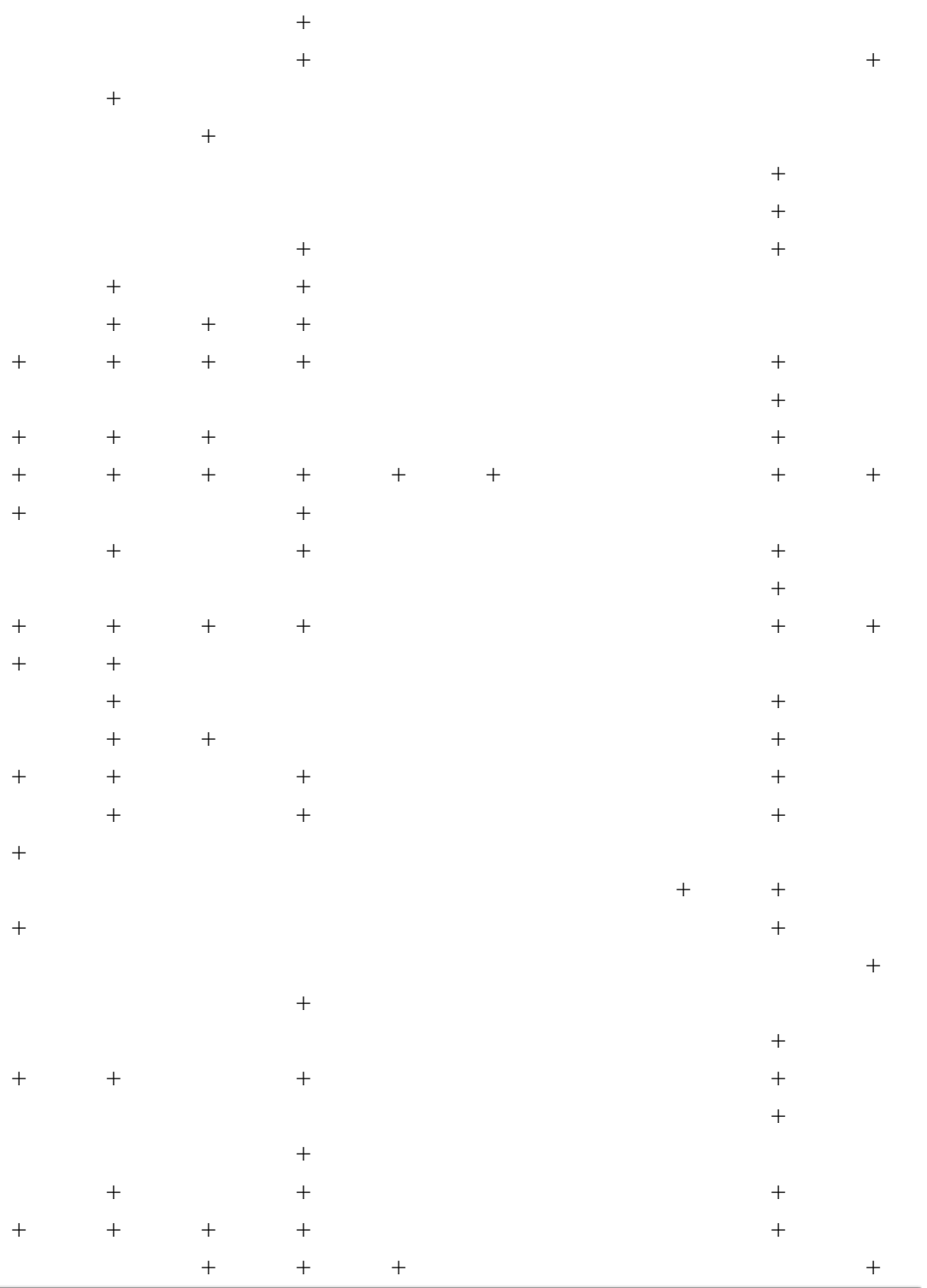

"+" denotes the presence whereas "-" absence.

* Visual observations. ** Species considered as Near Threaten (NT) in IUCN red list 2013. 
Table 2. Distribution of decapods among sampling locations

\begin{tabular}{|c|c|c|c|c|c|c|c|c|c|c|}
\hline Species & 足 & ప્ర & D & 曰 & 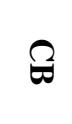 & ๑ొ & $\underset{v}{Z}$ & $\underset{r}{Z}$ & 胥 & $\overbrace{0}^{0}$ \\
\hline \multicolumn{11}{|l|}{ Xanthidae } \\
\hline Atergatis floridus & - & - & - & - & - & - & - & - & - & + \\
\hline Atergatis integerrimus & - & - & - & - & - & - & - & - & + & - \\
\hline \multicolumn{11}{|l|}{ Portunidae } \\
\hline Charybdis hellerii & + & + & + & + & + & - & - & - & + & + \\
\hline \multicolumn{11}{|l|}{ Menippidae } \\
\hline Menippe rumphii & + & + & + & + & + & - & - & - & + & + \\
\hline \multicolumn{11}{|l|}{ Grapsidae } \\
\hline Grapsus albolineatus & + & + & - & - & + & - & + & + & + & + \\
\hline
\end{tabular}

According to studies by NARA (1996) and University of Moratuwa (2011), only Grapsus albolineatus was found common in NARA (1996), and there were no crab species common with the University of Moratuwa (2011) study. Further, Atergatis floridus, Atergatis integerrimus, Charybdis hellerii and Menippe rumphii species considered to be new recordings for port biodiversity.

Based on Jayamanne (2011) there are three main commercially available marine crab species in Sri Lankan, i.e., Scylla serrata, Portunus pelagicus and Portunus sanguinolentus. However, none of these crabs were recorded from the present study. Though, the findings of NARA (1996) consist of all these commercial species and findings of University of Moratuwa (2011) consist of Portunus pelagicus. Therefore, according to the present study and previous literature, there was a significant difference in composition of
Portunus pelagicus can swim a considerable distance ranging from 2 to $10 \mathrm{~km}$ per day. However, as per the records from fisheries harbor which located close proximity to Colombo port, it was found that these species were caught from commercial prawn nets adjacent to Colombo port area where the distance is less than $10 \mathrm{~km}$ though they were not recorded within port premises during the study.

\section{CONCLUSION}

According to the present study, 45 species of ichthyofauna were recorded, where 44 species were belonging to Class Actinopterygii and only one species belonged to Class Chondrichthyes. Five species of decapod crabs recorded in this study were belonging to families Xanthidae, Portunidae, Grapsidae, and Menippidae. Among the study sites, the highest number of fish species were recorded from the sites SJ followed by PJ, TL, and SAGT whereas 
in terms of diversity the highest number of crab species were observed from PVQ and SJ. Among the faunal assemblage, none of the fishes and crabs were recorded as introduced or invasive in our waters. However, according to the findings, 30 species of fishes and 4 species of crabs were new records for the Colombo port environment, and two near threaten fishes, Epinephelus malabaricus, and Epinephelus coioides) were also recorded.

\section{ACKNOWLEDGMENTS}

Authors would like to extend sincere gratitude for the support given by Marine Environment Protection Authority (MEPA), granting permission by Sri Lanka Ports Authority (SLPA) and helpful hand given by the SLPA staff.

\section{REFERENCES}

ALLEN G. Marine Fishes of South-East Asia: A Field Guide for Anglers and Divers. C. E. Tuttle. 2002; 1- 292.

BENNET C, BUTCHER R \& STEVENS L. Baseline monitoring of Port of Tarakohe, Golden Bay. Cawthron Report No.1143. 2006. CURRIE MR, MCARTHUR MA \& COHEN BF. Exotic marine pests in the port of Geelong, Victoria. Marine and freshwater institute, 1998; 8: 1-39.

ESCHMEYER WN. Catalog of fishes, Institute for Biodiversity and Sustainability. California Academy of Sciences. 2013; http://research.calacademy.org. Accessed on $3^{\text {rd }}$ September 2013.
FROESE R \& PAULY D. FishBase. World Wide Web electronic publication. 2013. http://www.fishbase.org. Accessed on $27^{\text {th }}$ August 2013.

FRUSHER SD, GIDDINS RL \& SMITH TJ. Distribution and Abundance of Grapsid Crabs (Grapsidae) in a Mangrove Estuary: Effects of Sediment Characteristics, Salinity Tolerances, and Osmoregulatory Ability. Estuaries, 1994; 17(3): 647-654.

HEWITT CD \& MARTIN RB. Revised protocol for baseline surveys for introduced marine species: Survey design sampling protocols and specimen handling. Centre for Research on Tntroduced Marine Pests. Technical Report No. 22. CSIRO Marine Research, Hobart. 2001; 1-46.

INGLIS G, GUST N, FITRIDGE I, FLOERL O, WOODS C, HAYDEN B \& FENWICK G. Port of Gisborne Baseline survey for nonindigenous marine species. Biosecurity New Zealand Technical Paper No: 2005/11, 2006; 180.

INGLIS G, GUST N, FITRIDGE I, FLOERL O, WOODS C, KOSPARTOV M, HAYDEN B, FENWICK G. Port of Lyttelton Second baseline survey for non-indigenous marine species. MAF Biosecurity New Zealand Technical Paper No: 2008/02, 2008; 1-156.

ISSG (INVASIVE SPECIES SPECIALIST GROUP). The Global Invasive Species Database. 2013. http://www.iucngisd.org/gisd. Accessed on $2^{\text {nd }}$ September 2013.

JAYAMANNE, SC. Crab Resource of Sri Lanka. National Aquatic Resources Agency. 2011. 
JOSEPH L. National Report of Sri Lanka on the Formulation of a Transboundary Diagnostic Analysis and Strategic Action Plan for the Bay of Bengal Large Marine Ecosystem Programme. Report of FAO/BOBLME Programme. Chennai India. 2003; 1-125.

KANGAS MI. Synopsis of the biology and exploitation of the blue swimmer crab, Portunus pelagicus Linnaeus in Western Australia. FISHERIES RESEARCH REPORT NO. 121. 2000; 1-25.

KENT CS \& MCGUINNESSK. Spatial and temporal variation in relative numbers of grapsid crabs (Decapoda: Grapsidae) in northern Australian mangrove forests. The Beagle, Records of the Museums and Art Galleries of the Northern Territory, 2010; 26: 79-87.

LEE CS \& MENU B. Effects of salinity on egg development and hatching in grey mullet Mugil cephalus L. Journal of Fish Biology, 1981; 19(2): 179-188.

LEE SY. Ecological role of grapsid crabs in mangrove ecosystems: a review. Marine and Freshwater Research, 1998; 49(4): 335-343.

NATIONAL AQUATIC RESOURCES RESEARCH AND DEVELOPMENT AGENCY (NARA). Colombo Port Extension Project Environmental Survey Biology. 1996; 19-25.

NEIL KM \& STAFFORD H. Port of Thursday Island - Baseline Surveys For Introduced Marine Pests. Preliminary Report of the March 2004 Port-Wide Field Survey. CRC Torres Strait and Queensland Department of Primary
Industries and Fisheries, report to Ports Corporation Queensland, 2004; 1-13.

PALOMARES MLD \& PAULY D. SeaLifeBase. 2013 Available at: https://www.sealifebase.org. Accessed on $27^{\text {th }}$ of August 2013.

RAJASURIYA A. Condition of reef habitats in Sri Lanka. In Lindon, O., Souter, D., Wilhelmsson, D., Obura, D. (eds.). CORDIO Status Report 201-2002, CORDIO/SIDA/University of Kalmar. 2002; 250.

RAJKUMAR JSI \& MILTON MCJ. Biochemical Markers of Oxidative Stress in Mugil cephalus Exposed to Cadmium, Copper, Lead and Zinc. International Journal of Pharma and Bio Sciences, 2011; 2(3): 41-49.

SILVA KHGM \& SILVA PK. An Ecological Study of the Mangrove Fauna in the West Coast Of Sri Lanka. CEYLON J. SCI. (BIO. SCI.), 1986-87; 19-20.

TAVARES M. True Crabs. In Carpenter K E (ed) The living marine resources of the western central Atlantic. Volume 1. Introductions, mollusc, crustaceans, hagfishes, sharks, batoid fishes and chimaeras. FAO species identification guide for fishery purposes and American Society of Ichthyologist and Herpetologist Special Publication No.5, Rome, FAO, 2002; 1-600.

UNIVERSITY OF MORATUWA (UM). Proposed Colombo Port City Development Project, Galle Face Colombo. 2011; 113-121.

WALTHAM NJ, TEASDALE PR \& CONNOLLY RM. Use of flathead mullet 
M.M.K.I. Marasinghe \& R.R.M.K.P. Ranatunga

(Mugil cephalus) in coastal biomonitor studies:

Review and recommendations for future studies. Marine Pollution Bulletin, 2013; 69: 195-205.

WORLD REGISTER OF MARINE SPECIES

(WORMS). 2012. http://www.marinespecies. org. Accessed on $8^{\text {th }}$ of September 2013. 